\title{
DESIGN E MIMESE: UMA REVISÃO SISTEMÁTICA DA LITERATURA
}

\author{
Antônio Henrique Silva Nogueira /UFPE \\ Amilton José Vieira de Arruda /UFPE
}

\section{RESUMO}

Este artigo tem como objetivo fazer uma revisão sistemática da literatura referente ao tema da mimese no contexto do design, no intuito de compreender a interação epistemológica entre ambos, especialmente em dois segmentos distintos: no campo teórico interdisciplinar, assim como, em aplicações metodológicas no que se refere à área empírica do design. Para tal, foi utilizado o protocolo metodológico de Kitchenham e Charters (2007) para o planejamento, a condução e o relatório da revisão. No decorrer da fase de condução, aplicando-se os devidos filtros de busca e excluindo os artigos que não atendiam os objetivos preestabelecidos, foram selecionados 29 artigos oriundos do banco de dados Scopus. A partir da análise do material obtido, foi verificado a recorrência do caráter empírico na relação entre mimese e design, a utilização dos termos "alvo" e "fonte" para se referir a semântica mimética, a colaboração de grupos focais, a eficiência da analogia como ferramenta cognitiva, a vasta interdisciplinaridade, a inspiração na natureza, a metáfora homem máquina e também algumas metáforas sociais.

Palavras-chave: Design; Mimese; Metáfora, Analogia; Métodos Criativos.

\section{Introdução}

Por definição, de acordo com o dicionário Michaelis (2021) o termo "mimese" em português ou mesmo "mimesis", quando utilizado na língua inglesa, significa a imitação ou a representação da realidade. Na literatura do design, o conceito de mimese com esta conotação, aparece também por outros dois sinônimos: "analogia (analogy)", semelhança entre coisas ou fatos; e por "metáfora (metaphor)", "figura de linguagem em que uma palavra que denota um tipo de objeto ou ação é usada em lugar de outra, de modo a sugerir uma semelhança ou analogia entre elas; [...] símbolo." (DICIONÁRIO MICHAELIS, 2021).

Desta forma, fica claro o sentido de "imitação de algo" nos termos citados, entretanto é preciso elucidar outra questão acerca da mimese, ao que se refere à sua abrangência. Pois, por possuir um sentido amplo, conceitos de mimese estão presentes em diversas áreas do conhecimento, a exemplo da psicologia, do marketing, da arquitetura, da matemática, da história, da filosofia, da informática, das artes visuais e obviamente do design. No entanto, especialmente nesta última área, o argumento mimético aparece diluído e fragmentado em teorias e métodos quase sempre de modo secundário, sem a devida importância epistemológica ou somente de modo empírico, quando aplicado a algum método de criação, apresentando lacunas teóricas significantes. 
Isto posto, esta revisão se faz necessária para investigar a fundo como a mimese está relacionada ao design, e se a premissa de que há uma lacuna teórico-metodológica atrelada ao contexto da área é de fato verdadeira.

\section{Mimese como conceito}

A principal característica da mimese, é que existem sempre duas entidades que compõem o conceito da obra: - a fonte - o objeto de inspiração; e - o alvo - artefato que foi criado a partir das influências da fonte original. A verossimilhança entre ambas pode ocorrer de diversos modos, contemplando aspectos "práticos, estéticos ou simbólicos" (LOBACH, 2001) e com graus de semelhança distintos, desde o idêntico, quando o alvo é muito semelhante à fonte de inspiração; ao mínimo indício de semelhança, neste caso, seria algo próximo ao mais abstrato possível. Para além disso, vale também destacar que o processo de fruição perceptiva de um objeto mimético permeia a subjetividade do usuário, suas experiências prévias e memórias, assim como o filtro cultural e temporal no qual objeto e sujeito estão inseridos. Neste sentido, a semiótica é uma ferramenta interessante para análise do objeto mimético por considerar sistematicamente "a relação entre objeto e representação". (PIERCE, 1995)

Na filosofia clássica, Platão e Aristóteles dão destaque distintos à mimese em suas escrituras. Aristóteles, define a mimese poética como "A recriação de entes por intermédio de uma imitação criativa" (ARISTÓTELES, 2009). O filósofo grego, acreditava que a representação da realidade não deveria retratar o mundo real como ele é, mas sim, como ele deveria ser. Para isso, ele indica 5 formas de como modificar aquilo que será imitado a fim de passar a mensagem pretendida: “(1) transfiguração, ou mudança de material, uso ou estado; (2) adição; (3) subtração; (4) composição, uma conjunção de duas ou mais formas sem que haja uma forma principal; e (5) alteração." (PULS, 2006 apud BOSI; PINHEIRO, 2019, p. 167).

Já Platão, como argumentam Bosi e Pinheiro (2019), tem uma ideia de mimese restrita à imitação, de certo modo pejorativa, pois ele define esta questão sob a ótica de sua recorrente ideia metafísica de "ideal", na qual são criados níveis de hierarquia em planos distintos, consequentemente, em primeiro plano está o mundo inteligível - o mundo dos Deuses - . Sendo assim, a criação de algum artefato fruto da ação humana estaria em um segundo plano, pois tal artefato poderia chegar ao máximo a aparentar com alguma criação divina, mas sempre teria um status inferior. Portanto, seguindo a lógica do filósofo grego, o processo de mimese, principalmente aquele que selecione como fonte de inspiração algum elemento da criação humana, considerado algo hierarquicamente 
mais distante do mundo inteligível, estaria em um nível inferior na régua platônica de virtude, algo próximo à "imitação da imitação".

De acordo com Gagnebin (1993), alguns vários séculos depois, o filósofo alemão Theodor Adorno, assim como Platão, se posiciona de modo bastante crítico à mimese, desta vez ele se refere à passividade do sujeito diante do processo mimético, aproximando-se dos conceitos de Freud para dissertar sobre o tema, adorno acredita que haveria uma "pulsão de morte" no processo mimético, pois a assimilação ao outro seria a morte do próprio sujeito, seu desaparecimento. Portanto, o "medo de perder o eu" seria uma forma de ausência crítica entre o sujeito e aquilo que ele representa, e somente a teoria poderia dar sentido às metáforas contidas no processo mimético, pois de acordo com o filósofo a apropriação de "materialidades" alheias é preciso que haja mediação.

Coincidentemente, segundo Gagnebin (1993), o também filósofo alemão Walter Bejamim esboça uma teoria da mimese que se contrapõe às teorias de Platão e Adorno, e que se assemelha à teoria de Aristóteles. Embasada na concepção mimética da linguagem, e de cunho universal, ele admite que o homem produz semelhanças porque reage às semelhanças do mundo. Para Benjamin, a escrita, a pintura, a dança e outras demais linguagens se apoiam na ideia de mimese, e até mesmo uma brincadeira de criança se apropria desse conceito. Portanto, a atividade mimética é sempre uma mediação simbólica e desse modo não se reduz a uma simples imitação, muito pelo contrário, o que possibilita uma nova reconfiguração de ambas entidades envolvidas: fonte e alvo. E até mesmo quando essa imitação não está presente na origem, ele afirma que ocorre o que seria a "semelhança não-sensível" (unsinnliche Ähnlichkeit), sendo assim, a linguagem seria o último grau da linguagem mimética.

\section{Mimese como método no design}

Há, ao longo da história do design, diversos exemplos nos quais a noção de familiaridade entre um novo produto (inovador) e o seu respectivo público-alvo é explorada de maneira conscientemente planejada. Podemos citar como exemplo deste fenômeno: o design dos primeiros aparelhos de rádio. Pois, de acordo com Adrian Forty (2007), quando as transmissões de rádio começaram em 1920, os aparelhos eram "montagens grosseiras de receptores, fios e válvulas", ou seja, pouco atrativos. Para criar uma maior aceitação dos consumidores, foram propostas algumas soluções que remetessem a algo já bastante familiar, seja à imitação de mobílias antigas ou ao acoplamento à mobiliários com outra finalidade, como uma poltrona por exemplo, de modo a esconder os circuitos elétricos. Até que finalmente, a partir de uma maior familiaridade do público ao universo radiofônico, foi possível 
que o design do referido dispositivo fosse concebido dentro de um estojo futurista, simbolizando algo novo e original, sem maiores estranhamentos.
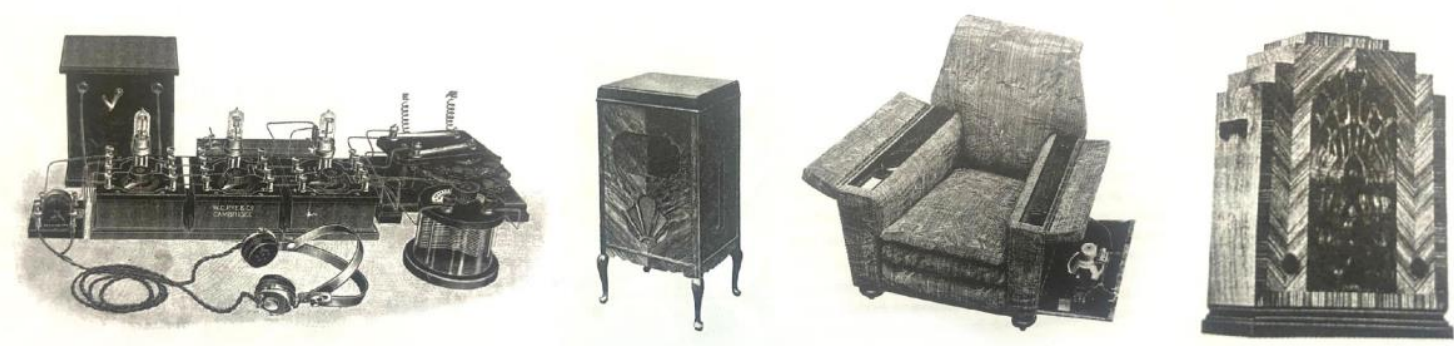

Figura 1. Evolução do rádio no início do séc. XX.

Fonte: (FORTY, 2007). 
Para além do exemplo do rádio, podemos citar diversos outros casos, como: o resgate do historicismo neoclássico, e sua intenção em imitar a poética clássica remetida à antiguidade grega e romana, a fim de transmitir os valores iluministas. Assim como, já no recente universo digital, a criação dos leitores de e-books que se aparentam aos livros físicos em forma, simbologia, tamanho e algumas funcionalidades, como virar as páginas e marcar o texto, por exemplo.

Contudo, a inspiração também pode ser em algo proveniente da natureza - a Biomimética - sobre este tema em específico podemos citar as duas revisões realizadas por Alice A. M. de Sá et al., ambas em 2020, a primeira intitulada "Design e Biomimética: uma revisão sistemática da literatura" a nível mundial, e a segunda com o título "Design e Biomimética: Uma Revisão sobre o Estado da Arte no Cenário Brasileiro" a nível local. Além dessas revisões sobre o tema biomimético, também podemos mencionar o artigo “Identificação de Características Morfológicas em Artefatos Inspirados na Natureza" de autoria de Theska Soares et al. (2021) em que é caracterizada as principais categorias estéticas dos artefatos bioinspirados, como: mimese; complexidade, formas orgânicas e geométricas, fractais, eficiência estrutural, modularização, simetria e escala.
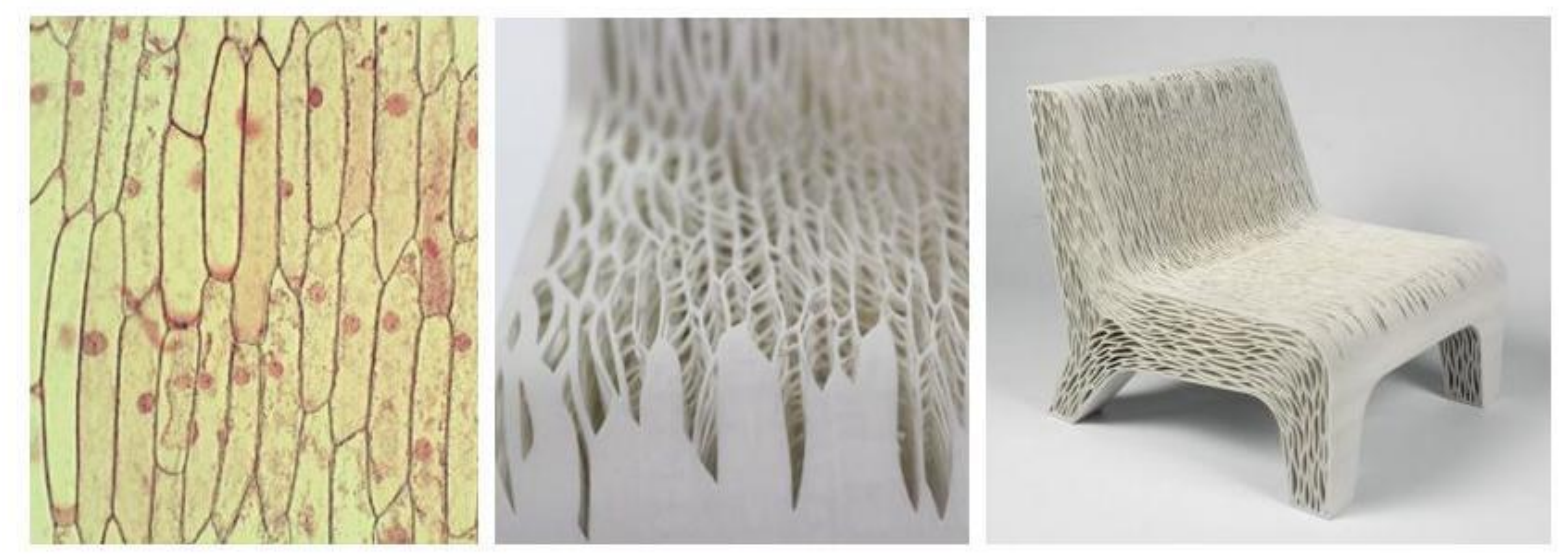

Figura 1. Cadeira biomimética projetada por Lilian van Daal inspirada em estrutura celular da planta. Fonte: (TAVSAN; SONMEZ, 2015). 


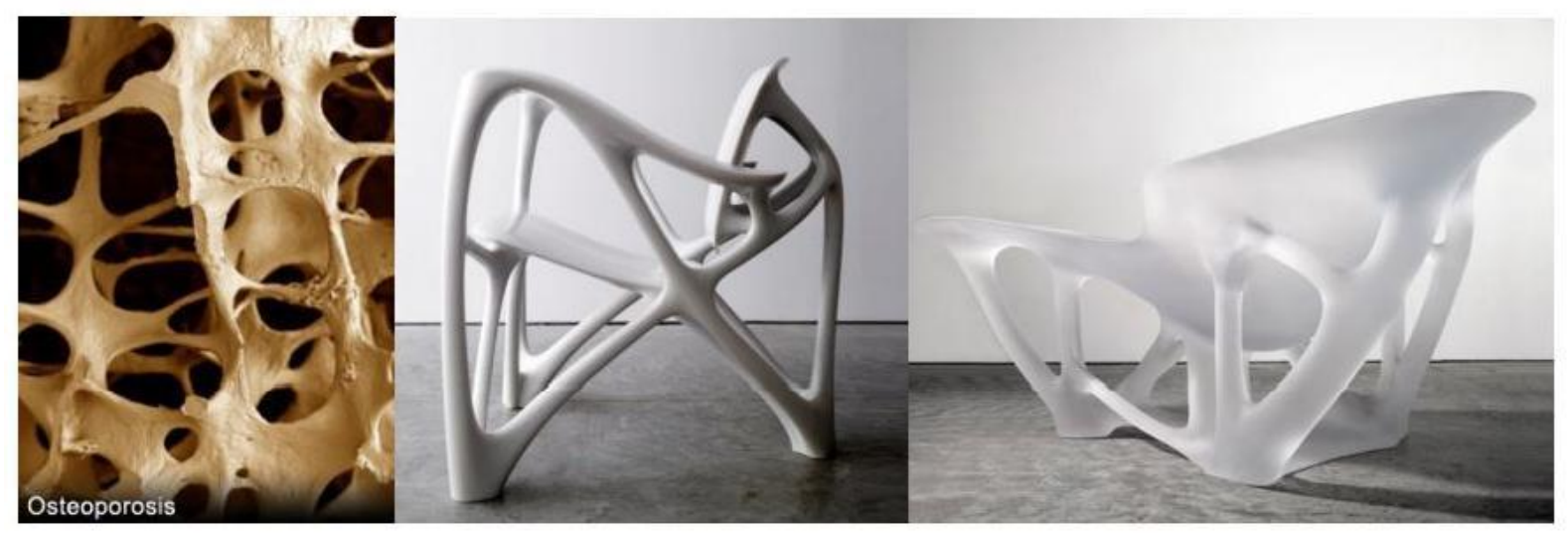

Figura 2. Cadeira biomimética projetada por Joris Laarman inspirada em estrutura óssea com osteoporose. Fonte: (TAVSAN; SONMEZ, 2015)

Todas estas abordagens, consistem em criar algum tipo de vínculo entre o produto e o sujeito consumidor, utilizando elementos já existentes na memória do usuário, para que a percepção final sobre o produto não seja de pleno estranhamento, ocasionando uma aceitação maior e mais fácil já no primeiro contato visual. Desse modo, a mimese, ou seja, a imitação de algo que já está consolidado no imaginário coletivo, pode ser uma alternativa eficaz para tal objetivo.

No design, a mimese pode ocorrer de diversas formas, seja com foco na "função prática, estética ou simbólica" (LOBACH, 2001) de algo, e essa fonte de inspiração pode ser uma infinidade de coisas, seja isso algo concreto como um edifício, um elemento da cultura ou algum tipo de artefato histórico, etc. ou algo completamente abstrato como um pensamento, como a música e até mesmo como a matemática. Tudo isso pode ser reconfigurado e ressignificado em um processo de mimese. No entanto, é coerente a princípio, separar os tipos de mimese em dois grandes grupos: 1- a mimese de elementos naturais, da referida criação "divina", o que seria a Biomimética; 2- a mimese de elementos artificiais, como elementos da cultura, criados pelo homem.

Tabela 1. Tipos de Mimese

Fonte: Autores

\begin{tabular}{ll}
\hline \multicolumn{1}{c}{ Natural } & \multicolumn{1}{c}{ Artificial } \\
\hline Estruturas orgânicas da fauna e da flora & Artes (Arquitetura, Pintura, Dança) \\
Fractais & Cultura (Artesanato, Artefato, Imaginário) \\
Padrões da natureza & Matemática (Design Paramétrico) \\
\hline
\end{tabular}

No entanto, no campo do design, em pesquisa preliminar foi constato que há uma lacuna teórica sobre métodos de mimese, metáfora ou analogia, apesar de existir muito material se referindo à esses termos, é verificado que em muitos casos existe apenas um modelo prático, um método, 
geralmente criado pelo autor intuitivamente, mas que não se fundamenta em modelos preexistentes específicos de mimese. Como exemplo podemos citar os criativos trabalhos: "Design de Joias a Partir de Aspectos Plásticos da Dança Contemporânea" (E. P. Calegaria; C. G. Hoelzelb, 2011) e "Índios Kariri: o grafismo do artefato para a criação de uma fonte tipográfica digital” (SILVA, R. S.; LEVY, A. D.), ambos apresentam processos miméticos baseados em elementos da cultura como fonte de inspiração, respectivamente, na dança e no artesanato indígena.
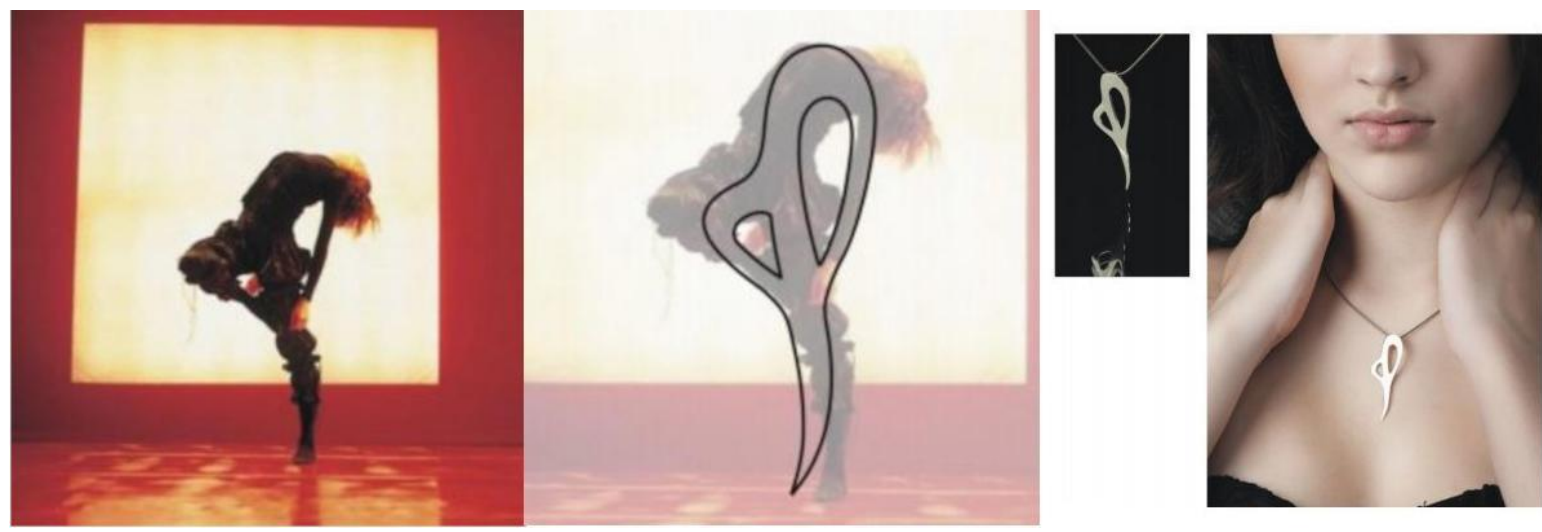

Figura 3. Joia criada a partir de inspiração em aspectos plásticos da Dança Contemporânea. Fonte: (E. P. Calegaria; C. G. Hoelzelb, 2011).
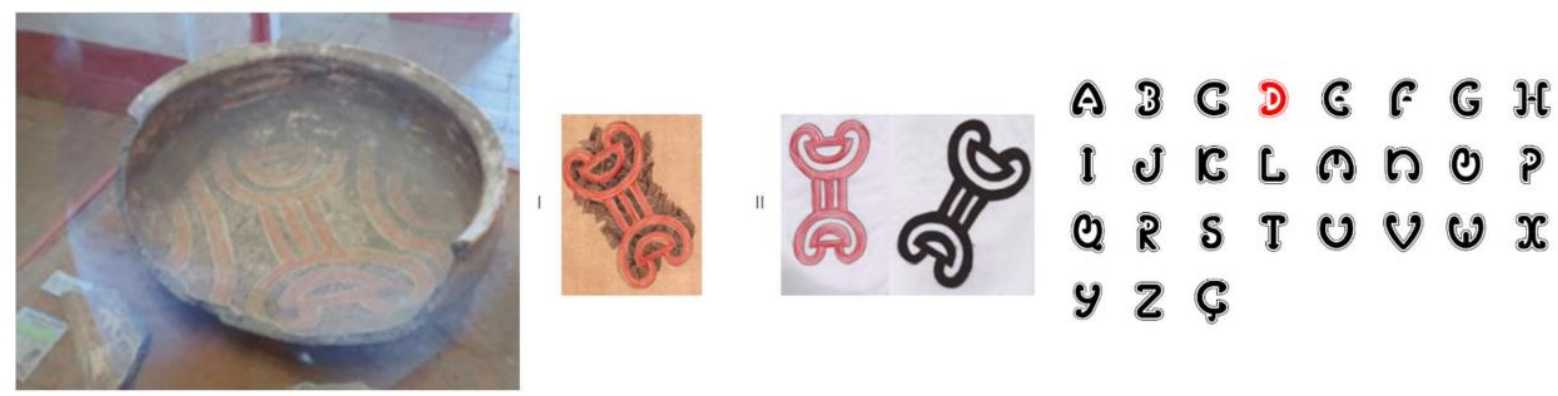

Figura 4. Tipografia criada a partir de inspiração em artesanato indígena do povo Kariri. Fonte: (SILVA, R. S.; LEVY, A. D., 2017). 


\section{Procedimentos Metodológicos (Protocolo)}

O protocolo adotado foi criado a partir de uma síntese das diretrizes estabelecidas por Kitchenham e Charters (2007) na qual os autores definem 3 etapas a serem seguidas: Planejamento, consiste na identificação da necessidade da revisão e na formulação da questão de pesquisa; Condução, Consiste na busca e seleção dos estudos primários, na avaliação da qualidade, na extração dos dados, na sumarização e síntese dos resultados e na interpretação dos resultados; Relatório: Consiste na escrita do relatório/artigo propriamente dito.

\section{Planejamento}

O intuito inicial é compreender como a mimese se relaciona com o design e qual a importância dos métodos de analogia na atividade projetual, especificamente no que se refere aos métodos criativos. Outra questão importante envolve a verificação da existência de uma possível lacuna do corpo teórico-conceitual sobre o tema e a verificação de uma possível sistematização ou fragmentação desse conhecimento. Sendo assim, inicialmente a pesquisa pretende responder a seguinte pergunta:

Questão de Pesquisa (QP):

"Como se dá a relação entre mimese e design?"

\section{Condução}

A partir de pesquisa exploratória inicial, percebeu-se que as informações contidas na literatura sobre a relação entre design e mimese são fragmentadas, muitas vezes contidas em pesquisas sobre métodos criativos, ou quase sempre descritas por outros termos (palavras-chave) com significados semelhantes, como: analogia, metáfora ou referência. Para tanto, foi preciso além de identificar esses termos, verificar as ocorrências da mimese em outras áreas do conhecimento, como na filosofia, e psicologia em busca de teorias, e no design e na arquitetura no que se refere à modelos modelos práticos, tudo isso para elucidar amplamente sobre o conceito de mimese. Para isso, foi preciso gerar a seguinte string de busca.

String de Busca:

Fazendo a interseção dos principais termos referidos à mimese na literatura do design, com o próprio termo "design", e utilizando todos os termos na língua inglesa para maior abrangência global foi possível formular a seguinte string de busca: "design" AND (“mimesis" OR "metaphor" OR "analogy"). 
Para tanto, foram encontradas além desses termos principais, os seguintes termos correlacionados:

"método de design"; "processo de design"; "métodos criativos"; "geração de ideia”; "representação"

e "iconografia".

Critérios de inclusão e exclusão:

Serão selecionados os artigos que contiverem ao menos 1 critérios de inclusão, e serão excluídos os artigos que contiverem ao menos 2 critérios de exclusão. Para cada critério de inclusão contido no artigo será atribuído uma estrela ( $\star$ ) em sua classificação. Não será critério de exclusão alguma limitação de datação ou de idioma, ou classificação por qualidade, pois o objetivo inicial pretendido é identificar a abrangência do tema.

Tabela 2. Critérios de Inclusão e Exclusão

Fonte: Autores

\begin{tabular}{ll}
\hline \multicolumn{1}{c}{ Inclusão } & \multicolumn{1}{c}{ Exclusão } \\
\hline$\star$ Ser das áreas das artes, design ou arquitetura & Não é da área do design ou arquitetura \\
$\star$ Possuir alguma elucidação teórica sobre mimese & Não possui informação teórica sobre mimese \\
$\star$ Possuir algum método empírico criativo de mimese & Não possui método empírico criativo de mimese \\
$\star$ Se referir à função estética ou simbólica de algo & \\
$\star$ Existir um artefato final como resultado do processo & \\
\hline
\end{tabular}

Tabela 3. Artigos Selecionados (Base de Dados: Scopus)

Fonte: Autores

\begin{tabular}{|c|c|c|c|}
\hline Título do Artigo & Autor(es) & Classificação & Contribuição \\
\hline $\begin{array}{l}\text { A BLENDED METHOD FOR } \\
\text { GENERATING CREATIVE PRODUCT } \\
\text { CONCEPTS }\end{array}$ & $\begin{array}{l}\text { Hung-Hsiang } \\
\text { Wang }\end{array}$ & $\begin{array}{l}\text { Metodológico } \\
\star \star \star \star\end{array}$ & $\begin{array}{l}\text { Aplicação de método criativo baseado } \\
\text { em elemento da cultura de Taiwan para } \\
\text { criação de artefato conceitual, a } \\
\text { luminária "Dragon Dancing". }\end{array}$ \\
\hline $\begin{array}{l}\text { A STUDY ON INFLUENCE OF } \\
\text { ANALOGY IN PRODUCT DESIGN } \\
\text { PROCESS }\end{array}$ & $\begin{array}{l}\text { Jim J Seelan; } \\
\text { Rajesh R }\end{array}$ & $\begin{array}{l}\text { Metodológico } \\
\star \star \star\end{array}$ & $\begin{array}{l}\text { Busca entender o significado da } \\
\text { analogia no Processo de } \\
\text { Desenvolvimento de um Novo Produto. }\end{array}$ \\
\hline $\begin{array}{l}\text { ANALOGICAL REASONING AND } \\
\text { MENTAL SIMULATION IN DESIGN: } \\
\text { TWO STRATEGIES LINKED TO } \\
\text { UNCERTAINTY RESOLUTION }\end{array}$ & $\begin{array}{l}\text { Linden J. Ball; } \\
\text { Bo T. } \\
\text { Christensen }\end{array}$ & $\begin{array}{l}\text { Teórico } \\
\star\end{array}$ & $\begin{array}{l}\text { Propõe aprofundamento na } \\
\text { compreensão sobre a "analogia" e } \\
\text { "simulação mental na concepção" } \\
\text { como estratégias de reduzir incertezas. }\end{array}$ \\
\hline $\begin{array}{l}\text { ARCHITECTURE AS SYMBOLIC } \\
\text { REVERENCE FOR NATURE: CASE } \\
\text { STUDIES: SEED CATHEDRAL - 21ST } \\
\text { CENTURY AND PIGEONS' } \\
\text { MONASTERY - 16TH CENTURY }\end{array}$ & E. S. Mashhadi & $\begin{array}{l}\text { Metodológico } \\
\star \star\end{array}$ & $\begin{array}{l}\text { Faz uma comparação entre dois } \\
\text { edifícios distintos, construídos em } \\
\text { tempos e lugares diferentes, que são } \\
\text { projetados a partir de inspiração na } \\
\text { natureza (biomimética). }\end{array}$ \\
\hline $\begin{array}{l}\text { CYBORGS Y DISEÑO DEL CUERPO: } \\
\text { ARTE Y TECNOLOGÍA, UNA MIRADA } \\
\text { DESDE FÉLIX DUQUE }\end{array}$ & $\begin{array}{l}\text { Ronald Durán } \\
\text { Allimant }\end{array}$ & $\begin{array}{l}\text { Teórico } \\
\star\end{array}$ & $\begin{array}{l}\text { Analisa as relações sobre arte, } \\
\text { tecnologia e corpo, sob o olhar da } \\
\text { analogia do corpo com as máquinas, } \\
\text { para isso utiliza a metáfora do cyborg. }\end{array}$ \\
\hline
\end{tabular}




DESIGN AND EVALUATION OF
METAPHOR PROCESSING SYSTEMS
ENACTING METAPHORS TO
EXPLORE RELATIONS AND
INTERACTIONS WITH AUTOMATED
DRIVING SYSTEMS

FIRING UP PSYCHE: MYTH, MOTORCYCLES, AND THE CULTURAL IMAGINATION

FUNDAMENTAL STUDIES IN DESIGN-BY-ANALOGY: A FOCUS ON DOMAIN-KNOWLEDGE EXPERTS AND APPLICATIONS TO TRANSACTIONAL DESIGN PROBLEMS

HANDLE WITH CARE! WHY AND HOW DESIGNERS MAKE USE OF PRODUCT METAPHORS

INFLECTED AND UNINFLECTED EXPERIENCE OF PICTURES

METAPHORS AS AN

UNCONVENTIONAL REFLECTIVE APPROACH IN ARCHITECTURAL DESIGN

METAPHORS OF RESONANCE FOR VISUAL COMMUNICATION DESIGN

MIMICKING GAMERS: UNDERSTANDING GAMIFICATION THROUGH ROGER CAILLOIS

MODALITIES OR SURFACES: POSTMODERN POETICS AND ARIDDLE

PERCEIVED ANALOGICAL COMMUNICATION IN DESIGN TEAMS: DEVELOPMENT AND VALIDATION OF A SCALE

PRINCIPLES OF LIGHTWEIGHT STRUCTURES IN THE SCULPTURAL CONCEPTIONS OF NAUM GABO

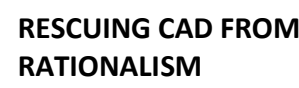

THE DESIGN IS THE GAME: WRITING GAMES, TEACHING WRITING

$\begin{array}{ll}\text { Ekaterina } & \text { Teórico } \\ \text { Shutova } & \star \\ \text { Helena } & \\ \text { Strömberg; } & \text { Metodológico } \\ \text { Ingrid } & \star \\ \text { Pettersson; } & \\ \text { Wendy Ju } & \end{array}$

Dennis Patrick Teórico

Slattery

Diana P.

Moreno;Alberto

A. Hernandez;

Maria C. Yang;

...

$\begin{array}{ll}\text { Paul Hekkert; } & \text { Teórico } \\ \text { Nazlı Cila } & \star \star \star \star \\ & \\ \text { Bence Nanay } & \begin{array}{l}\text { Teórico } \\ \star \star\end{array}\end{array}$

Teórico/Metodoló

HERNAN P. gico

CASAKIN

$\star \star \star \star$

Teórico

Veroni a Kell y

Vincenzo Idone

Cassone

JanneTapper

Teórico

$\star$

Daniel Graf;

Nicoleta Meslec;

Mark A. Clark

Metodológico

$\star \star$

Theresa

Neurohr

History;

Damiano Pasini

Richard Coyne;

Adrian

Snodgrass

Alice J. Robison Massachusetts
Revisão sobre características e avaliação de sistemas computacionais de processamento de metáforas.

Experimento com 27 participantes em workshop mostra que a analogia é um método eficiente de criar conceitos de design.

Análise estética sobre as diversas metáforas culturais contidas na motocicleta, como: o cowboy, o cavaleiro, o fora da lei, fetiche por velocidade etc.

Estudo de processos cognitivos, por analogia, para para exploração de soluções inovadoras para problemas transacionais. Envolvendo arquitetura da engenharia e serviços.

Analisa várias formas na concepção e seleção de metáforas para produtos enfatizando sua importância e o seus equívocos.

Interpretação da imagem inflectida ou não inflectida na percepção.

Aplicação da metáfora como ferramenta cognitiva de concepção.

Discute a metáfora da ressonância, e suas diversas abordagens, na comunicação visual.

Relação entre jogo e sociedade, analogias e gamificação.

Palco do teatro e cultura pós-moderna como metáfora da sociedade do capitalismo tardio.

investigação da analogia sob o ponto de vista dos receptores.

Um olhar sobre a estética escultória de Gabo, e a maneira como ele transmite leveza e equilíbrio através da analogia com estruturas óptimas, menor peso e máxima eficiência estrutural (analogia orgânica).

A computação como metáfora e inteligência artificial como processo de concepção.

Concepção de jogos como exercício de composição criativa escolar em analogia à composição escrita. 
THE EFFECTIVENESS OF METAPHORIC RESOURCES IN GRAPHIC INTERFACE DESIGN

THE IMPACT OF DESIGNERS' GOALS ON DESIGN-BY-ANALOGY

\section{THE INFLUENCE OF COLOR IN FRAGRANCE PERCEPTION DESIGNING PACKAGINGS FOR PERFUMES \\ THE INTANGIBLE MATERIAL OF INTERACTIVE ART: AGENCY, BEHAVIOR AND EMERGENCE}

THE JOURNEY AS CONCEPT FOR DIGITAL MUSEUM DESIGN

THE MACHINE CONCEPTION OF THE ORGANISM IN DEVELOPMENT AND EVOLUTION: A CRITICAL ANALYSIS

THE POTENTIAL OF DESIGN-BYANALOGY METHODS TO SUPPORT PRODUCT, SERVICE AND PRODUCT SERVICE SYSTEMS IDEA GENERATION

THE PRACTICE OF SMARTGEOMETRY

TWO FUNCTIONS OF ANALOGICAL REASONING IN DESIGN: A COGNITIVE-PSYCHOLOGY APPROACH

USER REQUIREMENTS FOR ANALOGICAL DESIGN SUPPORT TOOLS: LEARNING FROM PRACTITIONERS OF BIO-INSPIRED DESIGN
Franciso Felip

Metodológico

Miralles

Leyla Alipour;

Mohsen Faizi;

Asghar M.

Moradi;

Gholamreza

Akrami

Camila assis peres silva, Clice sanjar mazzilli

Joan Soler-

Adillon

Gunhild Varvin; Hilde Fauskerud; Ida Klingvall; Lin Stafne-Pfisterer; Ida Sannes Hansen; Mari Ravler Johansen

\section{Daniel J.}

Nicholson

Centre

Moreno

Grandas, Diana Paola; Blessing Luciënne; Yang Maria; Wood, Kristin

HUGH

WHITEHEAD

Architect

Willemien Visser

Gülşen Töre

Yargın; Roxana

Moroşanu Firth; Nathan Crilly
Teórico

Metodológico

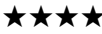

Teórico

\section{$\star \star$}

Metodológico

$\star \star$

Metodológico

$\star \star$

Teórico

$\star \star$

Metodológico

$\star \star$

Metodológico

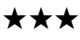

Teórico

$\star \star$
Explora a metáfora como método criativo para criar estruturas de navegação em design de interfaces.

Enfatiza a importância da seleção da fonte para a concepção do design baseado em analogia.

Cores como metáforas visuais para comunicação visual de embalagens de perfumes.

Arte interativa como metáfora da conversa.

A metáfora da viagem como concepção de experiência para desenvolvimento de museu digital.

Examina criticamente a metáfora de concepção do organismo como máquina (Machine Conception of the Organism).

Método de design por analogia voltado para o desenvolvimento de sistemas de serviços.

Técnicas matemáticas como concepção de projetos de arquitetura.

Abordagem cognitiva sobre a analogia no design como modo econômico de concepção.

Entrevistas para coleta de dados para aprimoramento de método de analogia bioinspirado. 


\section{Relatório}

Analisando o resultado desta revisão, fica evidente a complexa interdisciplinaridade e a diversidade de temas e aplicações de métodos que envolvem a mimese no campo design. Tal abrangência revela um enorme desafio em sistematizar todo esse conhecimento. No entanto, percebe-se algumas tendências, alguns padrões já previstos e que se confirmam no decorrer da pesquisa, como:

1 - O caráter empírico da aplicação da mimese na área do design, como exemplo podemos citar o interessante processo de criação da luminária "Drangon Dancing" (WANG, Hung-Hsiang, 2015) artefato baseado na cultura taiwanesa criado a partir do Blended Method, método que consiste em fazer uma mistura entre os elementos estéticos relevantes contidos no alvo e na fonte;

2 - Alvo e Fonte, termos utilizados para passar a noção de que o objeto mimético é composto pela união de significados envolvendo ele próprio e a simbologia da sua finalidade, e uma fonte de inspiração original;

3 - Grupos focais, por se tratar de analogias e metáforas, é recorrente a presença de grupos no desenvolvimento dos processos de concepção, sejam estudantes, designers ou usuários, portanto faz-se necessário algum tipo de feedback para as escolhas das fontes de inspiração e as metáforas a serem utilizadas no projeto, para isso as atividades em grupo são essenciais para resultados consistentes e eficazes nessas fases do projeto, como demonstram os artigos;

4 - Analogia como ferramenta metalinguística eficaz de criação de conceito, na redução do tempo de percepção da mensagem visual, "economia cognitiva" (VISSER, 1996), através da familiaridade e na eliminação de incertezas;

5- Interdisciplinaridade, além obviamente do design, áreas como psicologia, marketing, arquitetura, matemática, história, filosofia, informática, artes visuais são de alguma forma minimamente contempladas nesta revisão.

6 - Inspiração na natureza, em aspectos funcionais estéticos ou simbólicos;

7 - Analogia entre humano e máquina, essa analogia está presente na metáfora do cyborg, no conceito de inteligência artificial, nas interfaces dos softwares, etc.;

8 - Metáforas sociais, o teatro e os jogos eletrônicos trazem algum tipo de metáforas sobre a realidade social. 


\section{Conclusão}

Portanto, a conclusão desta breve pesquisa é que existe muito conteúdo a respeito da relação epistemológica entre mimese e design, no entanto este conteúdo apresenta-se bastante fragmentado e diluído em interseções interdisciplinares, de maneira muito diversa, e sem a amplitude e unidade necessárias para dar suporte teórico à prática projetual. Neste sentido, faz-se necessário para além desta revisão sistemática da literatura, a concepção de novas relações teóricas e aplicação de novos métodos empíricos, sistematizando o conhecimento adquirido a partir desta elucidação e reflexão inicial sobre este tema.

De modo prático, esta síntese permitiu uma maior ampliação sobre olhar da mimese como ferramenta projetiva no design, principalmente no que diz respeito à sua utilização com o objetivo de criar maior engajamento e aceitação do usuário, a partir da fruição perceptiva mimética como um facilitador cognitivo (VISSER, 1996). Para tanto, é preciso considerar a memória, subjetividade e o imaginário coletivo para gerar eficácia nas concepções estéticas dos artefatos ou serviços a serem desenvolvidos. Também ficou claro, a importância, de grupos focais durante o processo mimético, pois para que haja o pleno engajamento do usuário é preciso incluí-lo como protagonista do projeto de design, assim como é necessária a inclusão de outros designers e projetistas, para que todos possam de modo colaborativo, aperfeiçoar o método, escolher as melhores fontes de inspiração e criar e ressignificar as metáforas menos mais potentes possíveis. 


\section{Referências}

ARISTOTLE. Aristotle on the Art of Poetry, Project Gutenberg, 2009. Disponível em: <https://www.gutenberg.org/files/6763/6763-h/6763-h.htm>. Acesso em: 23 de julho de 2021.

BOSI, Felipe A.;PINHEIRO, Ethel. Retórica Aristotélica e Mimese no Projeto Arquitetônico: Os Casos "Pato", "Galpão Decorado" e "Guild House" de "Aprendendo com Las Vegas". Arquitetura Revista, Palmas, v.15, n.1, p.(162 - 178), Jan/jun, 2019.

CALEGARIA, E. P.; HOELZEL, C. G. Design de Joias a Partir de Aspectos Plásticos da Dança Contemporânea. Santa Maria: Universidade Federal do Rio Grande do Sul, 2011.

FORTY, Adrian. Objetos de Desejo: design e sociedade desde 1750. São Paulo: Cosac Naify, 2007.

GAGNEBIN, J. M. Do Conceito de Mímesis no Pensamento de Adorno e Benjamin. Perspectivas, São Paulo, v. 16, p. 67-86, 1993.

KITCHENHAM, Barbara; CHARTERS, Stuart. Guidelines for performing Systematic Literature Reviews in Software Engineering. Technical Report EBSE 2007-001, Keele University and Durham University Joint Report, 2007.

MICHAELIS. Moderno dicionário da língua portuguesa. São Paulo: Melhoramentos. Disponível em: $<$ https://michaelis.uol.com.br/>. Acesso em: 23 de julho de 2021.

LÖBACH, Bernd. Design Industrial: Bases para a configuração dos produtos industriais; tradução Freddy Van Camp - São Paulo: Blucher, 2001.

SÁ, Alice Araujo Marques de; VIANA, Dianne Magalhães. Design e Biomimética: Uma Revisão Sobre o Estado da Arte no Cenário Brasileiro. MIX Sustentável, [S.I.], v. 6, n. 5, p. 137-150, dez. 2020. ISSN 24473073. Disponível em: <http://www.nexos.ufsc.br/index.php/mixsustentavel>. Acesso em: 23 de julho de 2021.

SÁ, Alice Araujo Marques de. Design e Biomimética: uma revisão sistemática da literatura. Research Gate, 2020.

SOARES, Theska; NOGUEIRA, Antônio; ARRUDA. Amilton. Identificação de Características Morfológicas em Artefatos Inspirados na Natureza. In: ENSUS 2021: IX Encontro de Sustentabilidade Em Projeto, Florianópolis: UNIVERSIDADE FEDERAL DE SANTA CATARINA, 2021.

SILVA, Rosemary Severo da; LEVY, Aglaíze Damasceno. Índios Kariri: o grafismo do artefato para a criação de uma fonte tipográfica digital. In: Projética, Londrina, v.8, n.2, p. 29-50, 2017.

TAVSANA, Filiz; SONMEZB, Elif. Biomimicry in Furniture Design. In: 7TH WORLD CONFERENCE ON EDUCATIONAL SCIENCES, Atenas, 2015. Procedia - Social and Behavioral Sciences 197, p. 2285 - 2292, ELSEVIER, 2015.

WANG, Hung-Hsiang. A Blended Method for Generating Creative Product Concepts. International Colloquium of Art and Design Education Research. i-CADER 2014, p.311-321, 2015.

VISSER, willemien. Two functions of analogical reasoning in design: a cognitive-psychology approach. Design Studies, Grã-Bretanha, 17, p. 417 - 434, ELSEVIER, 1996. 